well-prepated specimen, the characteristics of the individual corpuscle are retained. In addition to the ruclei of the leucocytes, numerous small spherical granular bodies may be seen arranged for the most part in groups of five to twelve, like grapes on a stalk, though occurring also singly ; but their depth of staining is, however, less than that of the nuclei of the white corpuscle. To see these little bodies well a magnifying power of at least 600 diameters is required. The question naturally arises, Are these little bodies the result of some change, some breaking up of the corpuscular elements during the process of drying, to which the preparation has been submitted, or do they naturally exist in normal blood? My impression is that they actually do exist, as they are well seen in blood in which the greatest precautions against change have been taken, as in using the warm stage. They can also be seen on the cold stage $\left(0 \mathrm{C}^{\circ}\right)$ and by the ordinary method of examination. An attempt to estimate their number must necessarily meet with considerable difficulty owing to their tendency to group together, but the result of several enumerations by means of Gowers' hæmacytometer gives from 250,000 to 300,000 in a cubic millimetre of blood. Spherical in shape, their size varies from $2.5 \mu$ to $4 \mu$. At times these bodies appear to be fugitive, as they are seen to become rapidly fainter and disappear even whilst under the eve of the observer; this is probably due to the fact that their refractive index varies but little from that of the plasma, and as the plasma becomes tinted with hromoglobin so does the refractive index of the two become approximated. By far the best demonstration of these racemose bodies can be obtained by allowing a drop or two of Hayem's corrosive sublimate solution or Gowers' salt solution to flow under the cover-glass; it will then be seen that, in addition to the physical properties already enumerated, they possess that of adhesiveness, remaining sticking to the slide or cover-glass whilst the corpuscles are washed away. They also assume a faintly greenish. yellow colour, become somewhat flattened, and lose their granular appearance. In the examination of blood in disease I have not been able to satisfy my self that there is any variation with regard to the shape or number of these racemose bodies; but in a case of pernicious anæmia my observations have varied, in some samples of the blood their number was far below, whilst in others it was very much the same as in normal blood. In observations on the blood of animals the racemose corpuscles can be clearly seen, and in specimens of dog's blood taken from the superior and inferior cavæ, portal vein, and splenic artery and vein, there is no appreciable difference in their number. They are absent from the scrapings of Jymphatic glands, spleen, and the medulla of bones in the dog. All these facts, together with their power of staining with methyl-violet, and their similarity to the processes thrown out by a living leucocyte, have led me to the conclusion that these bodies are broken-up white corpuscles, or portions detached from the same.

Variuus observers, both English and foreign, in writing on the blood, have described small bodies as to the origin and ultimate destination of which different views have been held. Zimmerman ${ }^{2}$ described small vesicles which, he believed, ultimately became fully developed red corpuscles. Virchow also states that little corpuscles do undoubtedly occur in the blood; he thinks, however, that they are not destined to become red corpuscles, but are, on the contrary, old ones breaking up. Riess also mentions the existence in the blood of small corpuscles, and cautions the observer not to mistake them for micro-organisms Cornil and Ranvier, as well as Marius and Vanlair, describe, under the head of "microcytes," small spherical, highly refractive, red granules. But, perhaps, the most elaborate description is that of M. Hayem. ${ }^{3}$ I a series of papers he bring $₫$ forward evidence to prove the existence in the blood of man of elementary red corpuscles, which he has called hæmatoblasts. He states that Marius, Vanlair, and others are inaceurate when they describe the exi-tence in blood of small spherical granules, and that his own physiological and clinical researches show that these so-called microcytes are only globules modified by external agencies-in other words, that they do not exist in the blood. His further description of the hematoblast is very similar to that described by myself $a b s v e$, with the ove great exception that he regards their shipe as discoidal instead of spherical. To demonstrate

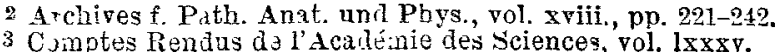

this clearly the blood is irrigated with a corrosive sublimate solution. It seems to me that blood irrigated with any fluid can hardly be called in a normal condition, and I venture to think that bis statement with regard to their discoidal shape is true only of blnor that has been placed under abnormal conditions by irrigation. I myself have not been able to verify his conclusions though the granules lose their crenation and become somewhat flattened as mentioned above. More recently Dr. Norris ${ }^{4}$ of Birmingham, in a series of papers which he has written on the existence in the blood of a third corpuscular element, alludes to the presence of small grauular bodies which he recognises as Hayem's bæmatoblasts, but affirms that these hæmatoblasts are simply due to the breaking up of his third corpusele. $\mathrm{My}$ observations may be summed up as follows :-

1. That there exist in the blood small spherical granular bodies arranged either singly or in groups.

2. That these small bodies stain with the aniline dyes in a similar manner to nuclear matter.

3. That they are fragments of white corpuscles, or portions detached from the same bodies.

\section{TROPHIC SKIN CHANGES OF NEUROTIC ORIGIN.}

By ALFRED SANGSTER, M.B. CAMB., PIYSICIAN IN CHARGE OF THE SKIN DEPARTMENT, CHARING. CROSS HOSPITAL.

\section{HERPES ZOSTER.}

Since the eruption on the skin known as Herpes Zoster has been recognised to be a manifestation of nerve trouble, observers have been on the qui vive to identify other lesions of the skin as due to a similar cxuse. The list of trophic disorders of the skin in immediate relation with nerve lesions is already a long one, and it is even probable that it will be added to in future, not so much by the recognition of fresh types of skin affection, as by the inclusion of some of those with which we are already familiar, but which have been thought to be due to constitutional and other causes.

Any association which may exist between particular types of skin eruption and special varieties of nerve lesion is at present almost entirely matter of surmise.

I propose to collect together under convenient headings cases bearing on the subject, most of which have already been recorded, not narrating them in detail, but merely stating illustrative facts. References will be given as a help towards the bibliography of the subject. It will be convenient to deal with those eruptions first which are associated with local nerve lesions. Having shown what is possible under such circumstances, the ground will be some. what cleared for conjecture with regard to nerve conditions of a more general character in their relation to cutaneous phenomena.

The eruption of herpes zoster is in its full development altogether sui generis -no one, having once seen it, fails to recognise it again. The clusters of various-sized vesicles following the distribution of the cutaneous nerves, the confluence of some of the vesicles to form shallow bullæ, are too well known to need minute description. In addition there is the definite clinical course pursued by the eruption, which is in itself quite characteristic. The symptom pain is such a prominent one in herpes zoster, and corresponds so closely to that which is described by patients suffering with neuralgic affections, that authors soon began to describe it as neuralgia. It may be noted, hewever, that intermittency or remittency is not laid special stress upon by patients suffer. ing with herpes zoster; nor do they often complain of the violent paroxysms such as accompany ordinary neuralgia of the fifth or sciatic. Entire lack of proportion between the severity of the pain and the cutaneous symptoms is constantly observed, and their relation as to time is so incon. stant, that the pain may precede the eruption for days or continue after its disappearance for months. It is asserted by some observers (e.g., Barensprung) that herpez zoster sometimes occurs without any neuralgia being present at all ; indeed, this may be said to be the rule with children amongst 
whom herpes zoster is not uncommon. No complaint of pain is made by these patients, excepting such as is probably of a smarting character and due to the eruption alone or its irritation by clothing, \&c. They are not kept awake at night, as is the case with adults and old people. This is in accordance with the comparative immunity enjoyed by children from neuralgic affections : taken with other facts mentioned above, it points to a certain independence between the eruption and the neuralgia.

Nearly all the phenomena which are seen in ordinary neuralgic affections are noticed in association with herpes zoster. Parrot ${ }^{1}$ has drawn attention to specially painful spots (foyers de douldeur of Valleix) to be found in herpes zoster. These correspond to the terminal branches of the intercostal nerves, and are specially liahle to become the seat of eruption. The centres of pain thus correspond to the centres of eruption. This fact does not appear to have gained the special attention of other observers. Anæstbe-ia has been observed in herpes zoster. Hutchinson ${ }^{2}$ re'ates a case where such numbness followed zoster of the fifth, that the part could be pricked with a pin without giving pain.

Motor disturbance, not at all an infrequent concomitant of neuralgia, is also noticed. Amongst others may be quoted a case reported hy Payne, ${ }^{3}$ where herpes zoster occurred in the distribution of the superficial branches of the anterior crural, having been preceded for three davs by temporary hemiplegia of the same side. The disturbances of nutrition accompanying ordinary neuralgic affections, such as congestion, inflammation, local erysipelas (Anstie ${ }^{-1}$, , of secretion, lacrymation, salivation, \&e., have been thought to find their analogue in the eruption of herpes zoster. 'Thi4, however, is denied hy Vulpian. The congestion, inflammation, \&c , accompanying neuralgia, he considers to be capable of explanation by supposing that irritation acting on the centripetal sensory nerves is transmilted to the vaso-motor centres of the pirts to which these nerves are distributed, that the tonic activity of these centres is suspended, and a paralysis of the vesse's of the corre-ponding reg on hrought about. The disturbances of secretion the same author con. siders as due to excito-secretory nerves. ${ }^{5}$ It will be shown later on that the skin changes in herpes zoster are probably not associated with the vaso-motor nerves.

Other disturbances of nutrition of the part afferted snmetimes accompany herves zister besides the eruptinn, such as inflammation of the eye in zoster of the fifth. ${ }^{6} \mathrm{~A}$ remarkable cave bearing upon this point has been recorded by Sir James Paget. ${ }^{7}$ An herpetic eruptiın, accompanied by neuralgia, occurred in the distribution of part of the second division of the fifth ; five sound teeth afterwards fell out on the side affected, exposing the necrosed alveolus. A similar case has been reported by Singer. ${ }^{8}$

The following cases serve to illustrate the connexion between herpes zoster and nerve injury :-

Charcot, in $1859,{ }^{9}$ reported the case of a man who received a bullet-wound in the thigh. Some time after the healing of the wound sharp contiuuous pain came on, starting from the cicatrix, and evidently following the course of the nerves. This neuralgia was accompanied by outbreaks of herpes seated over the skia of the painful part. In the same year and in the stme journal a siuilar case was recorded by Rouget, but in this iustance the bruised nerve over whose course the herpes appeared was seen lying at the bottom of the wound.

As bearing on the subject of herpez znater in connexion with traumatic injuries of the nerves, it is on'y right to allude to the valuable onservations of Mitchell, Morehouse, and Keen, if oulv to give promint noe to the remurkable fact that heroes, at lest in its typicd form, appears seldom, if ever, to have followerl the gunshot iujuries of nerves, which they had such a hundant opportunity of seeing. In allusion to the vesiculir diseases of the skin which followed nerve injury, Dr. Weir Mitchell says: $:^{10}$ - "These eruptious were somewhat peculiar, an' more like eczema than herpes. The eruption cousisted of small, srattered, acutely puinted vesicles, full of thin serons fluid; on the healthy skin they were laryer and drie lup without sfquelic; hut when situated on the thin, altered termments (glossy skin) they left behind

\footnotetext{
1 Considerations sur le Zuna, 1857. 2 Isronron Hosp. Reports, 1866. 3 Brit. Med. Jour., 1871 .

3 Leç ins sur l'Appireil Vaso $\lambda I$ ruteur, tom. ii., p. 492.

6 Hutchinson, loce cit. 7 Bitr. MIen. Journal, vol. ii., p $402,1866$.

8 Quoted b: Hougeot: Recherches sur quiques Troubles de Futrition

concécutives aux Affections des Nerfs. p. 112.1967

9 Journal de Physiologie, tom. ii., No. 5, 1859.

19 Injuries of Nerves, p. 155.
}

minute ulcers, which horribly increased the itching or burn. ing so constantly present. It was rare to see any case of glossy skin, especially with causalgia (burning pain), unattended by vesicles; but these were apt to come and go in successive crops, aud we soon observed that when present the burning pain was lessened : a fact which our patients also recognised. As a rule, the eruption was widely spread over the affected skin, and was not gathered into gioups."

It is evident that the eruption described was quite unlike berpes, the vesicles of which are just the reverse of small, scattered, and acntely pointed. The "coming and going in successive crops" suggests an herpetic nature, but the concluding sentence describing the arrangements of the anatomical elements of the eruption as being "widely spread "and not "gathered into yroups" is enough to put it out of the category of herpes. Two suggestions may be offered : 1. That the herpes was prevented from putting on its typical appearance in consequence of the atrophic condition of the skin, possibly of those elements specially concerned in herpes. 2. The eruption may have corresponded to that which is seen when herpes aborts ( $a$ by no means un. usual occurrence). In this condition only isolated points become visible either remaining papular or ultimately becoming vesicular; there is no surrounding redness, and the clustered arrangement is in a greater measure lost.

Following the cases of traumatic nerve injury associated with herpetic eruptions may be mentioned the cases where herpes has occurred as a cousequence of neuritis set up by the invasion of growths, exten-inn of inflammation, \&c. Such a case is related by Charcot, ${ }^{11}$ where herpes of the cervical reoion was caused by the compression to which the nerves which form the cervucal plexns were subjected by the extension of a canceruus growth. The post-mortem examination showed the nerve trunk tumefied, and of a vivid red colour: moreover, in the suinal ganglia, as well as the nerves, a microscopical examination demonstrated inflammatory changes. A similar case has been recorded by Ullivier. ${ }^{12}$

Lendet has proved cone'usively that poisoning by carbonic acid induces disturbance of the peripheral nerves, giving rise to symptoms of neuritis, followed by herpetic eruptions in the course of the nerves attacked. Hicroscopical examination proved the existence of the lesions of the nerve. ${ }^{13}$

Lastly must he mentioned Barensprung's oft-quoted case, as one in which an apparently spontaneous herpes zoster was shown to be associated with neuritis of the nerves distributed to the part at acked. In a child one year old a herpes zoster extended round one side of the thordx from the sixih to the ninth rib. After death, which occurred from tubercular disease, the roo's of the sixtb, seventh, and tighth intercostal nerves were increased in size, and of a red colour, in consequence of enlarged and tortuous vessels in the newrilemma. The diameter of the seventh intercostal nerve exceeded by more than half that of the eighth or ninth. The corresponding intervertebral ganglia were firmly adherent to the intervertebral canal ; their connective tissue presented an inflammatory redness, and they were decidedly increased in size. ${ }^{1 *}$

Although the fact must be accepted that herpes zoster is sometimes produced by neuritis of the sensory nerves, the evidence at present is of too slender a character to extend such a theory of cause to all cases of spontaneous nr idiopathic herpes zoster, however tempting it may he to do so.

The next question of interest which occurs is, What special elements, if any, wbich go to make up a sensory nerve are concerned in the production of herpes zoster? The following is a short résumé of some of the opinions held by Vulpian :-As observers $h$-sirate whether to accept the existence of the so-called trophic nerves, they may be left out of consideration for the present. The fibres which go to make up a sensory nerve are : (1) Vasn-motor fibres; (2) sympathetic motor fihres distributed to the cutaneous museles (arrectores vilorum) ; (3) fibres supplying glands; (4) sensory fibres properly so-called. It is scarcely possible that in herpes zoster we have to do with vaso-motor nerves. The condirion would prohably be one either of paralysis and dilatatiın of the vessels, or irritation and consequent occlu-

11 Diseases of the Nervous System, Srd. Soc. Trans., p. 24.

12 Quoted from Vulpian, op. cit., p. 552

13 Recherches sur les Trontiles des Nerfs periphériques et surtont des Vaso-JIoteurs consécutifs à l'Asphyxie par le Vapeur de Charbon, 1865. 14 Archiv fur Anatomie und Pbysiologie, No. 4, 1865. 
sion; but as regards the former, the cervical sympathetic has been divided an immense number of times in animals, and no physiologist has ever seen the least eruption on the face or ears as the result of vaso-motor paralysis. Conditions of vaso-motor paralysis are seen in the human subject, but they are not accompanied by herpetic eruption. The congestion in herpes zoster is rather secondary, not becoming intense until the eruption is fully out. If the condition were one of irritation and occlusion of the vessels, the skin about to become the seat of herpes zoster would pale, but this has not been observed. The fibres distributed to the muscles and glands are not likely to have any influence on the eruption of zona. There remain, then, only the sensory fibres.

One of the conditions invariably present in zona, traumatic or other, is a certain degree of continuity in the nerves attacked. One may suppose, then, that the irritation of which the nerves become the seat may set up functional disturbance in the trophic centres of these nerves, which may, through the agency of the remaining healthy fibres, react on those anatomical elements of the skin with which their peripheral extremities are en rapport. Thus would be produced a more or less profound disturbance of those nutritive acts which take place in these elements, their modification or perversion leading to the development of herpetic vesicles. ${ }^{15}$

\section{CASE OF FATAL CEREBRAL H AMORRHAGE. ${ }^{1}$}

By D. H. MONCKTON, M.D., F.R.C.S., PHYSICIAN TO THE STAFFORDSHIRE GENERAL INFIRMARY.

THE case I propose to bring under notice is briefly this. By the order of a coroner I made a post-mortem examination, and found a blood-clot the size of a small walnut, and weighing 201 grains, embedded in the left cerebral hemisphere, not in the lateral or any other of the ventricles, but just below the convolutions, on the upper convex surface of the brain, about an inch and a half to the lefi of the longitudinal fissure, and at the junction of the middle with the posterior third of the left hemisphere. I found the clot at the bottom of a suleus between two convolutions, giving me at once the idea that a small vessel in the pia mater had given way, the effused blood lacerating the grey cortical layer of brain tissue, and lodging itseli in the soft white brain matter below. The vessels of the dura mater and pia mater were generally congested, indeed gorged, with blood; and my attention was drawn to the spot described above by a slight extravasation beneath the visceral layer of the arachnoid, when on slicing away the convolutions the clot was found just below them. There were no external marks of injury to the scalp or skull; no fracture or fissure. I had seen the deceased once in life twenty-four hours before his death, in consultation; he was then unconscious, delirious, with dilated and inactive pupils. He was evidently dying of some brain affection. The history of the case was this: On a Saturday night eight days before his death, this young man of twenty-one was in a row in a public-house, and according to the evidence of eye-witnesses he received a heavy blow from the closed fist of a big powerful fellow between his eyes, which caused him to stagger back and bleed freely at the nose, but he was caught by the bystanders, was only momentarily stunned, and was able soon to walk out of the house and away to his home three or four miles distant. The following day, Sunday, he was out walking, and on Monday was at his work all day in a coal mine. On Tuesday morning he started to his work but the bleeding from the nose and mouth returned, and he was obliged to leave off work and return to his home very ill. On Wednesday he was first seen by a medical man, when he complained chiefly of his head. On Friday serious brain symptoms set in, he became comatose, delirious, and partially convulsed.

I gave evidence before the coroner's court and at the assizes, that in my opinion the blow had ruptured a vessel in the nose which bled freely externally, and a small vessel at the top and back part of the brain which bled internally, and formed the clot produced. That the clot, situated as it was near the surface of the brain, was of much less moment

15 Tulpian, op. cit., p. 555.
1 Read before the Staffurdshire Branch of the British Medical Association at its meeting at Stoke-upon-Trent, Nor. 24 th, 1881. than it would have been in the interior or at the base of the brain, and that death resulted from the congestion and inflammation of the membranes, which commenced only on the Tuesday morning, three days after the injury had been received. 'The coroner's jury returned a veidict of manslaughter against the man who dealt the blow, but he was acquitted before the judge of assize, who summed up in the prisoner's favour on the ground that the symptoms immediately following the blow were too slight to warrant the conclusion that the blow caused his death.

The questions of interest arising for discussion upon this case are : 1. When was this clot formed, immediately on receipt of the blow or gradually by slow leakage of the small ruptured vessel? (I may remark that the clot is solid through out, not laminated.) 2. Could the man walk about for two days, and do his work for one, with this clot in his brain?

In the discussion which followed the reading of the above paper, a general feeling was expressed that the clot was the result of the blow, and the cause of death.

Stafford and Rugeley.

\section{d a dititur}

\section{HOSPITAL PRACTICE, BRITISH AND FOREIGN.}

Nulla autem est alia pro certo noscendi via, nisi quamplurimas et morborum et dissectionum historias, tum aliorum tum proprias collectas habere, et inter se comparare.-MoaGAGNI De Sed. et Cars. Morb., lib. iv. Proomium.

\section{WESTMINSTER HOSPITAL.}

GENERAL PERITONITIS FOLLOWING PELVEO-PERITONITIS; DEATH.

(Under the care of Dr. STURGES.)

For the following notes we are indebted to $\mathrm{Mr}, \mathrm{C}$. Hebbert, medical registrair to the hospital.

Esther G-_ aged seventeen, housemaid, was admitted on the morring of Dec. 17 th with general peritonitis. The history obtained from a fellow-servant was that on the morning of the 13th, after having taken some tea, she com. plained of pains in the abdomen. She took to bed in the evening, and next morning suffered severe pains in abdomen, and sickness. A medical man was called in, and he gave her an enema, after which she had several motions during the day. The bowels were not open again before admission to the hospital. Pain and sickness were constant, and on the morning of admission the vomit was offensive.

On admission, the expression of patient was that of great anxiety; the face was pinched, the eyes were much sunken, and the skin was covered with cold sweat. The patient was very restless, and complained of severe pain in the abdomen. The pulse was very rapid, small, and thready; the abdomen tympanitic, distended, and tender to pressure. Opium and fomentations were ordered, but she never rallied, and died in a few hours.

Necropsy. - Rigor mortis present; face dusky; eyes sunken; body well nourished; areolæ of breasts brown; abdomen distended. On ovening the abdominal cavity, the intestines were found much inflated; the whole peritoneum, both visceral and parietal, presented the acute ramiform in: jection of recent peritonitis, the intestines being matted together with recent lymph; and there were two pints of turbid serous fluid in the abdominal cavity, with flakes of lymob. On raising the intestines, it was found that the pelvic cavity was separated from the general abdominal cavity by a thin layer of pseudo-membrane, incomplete from rupture on the right side. Beneath this membrane was a collection of thin purulent fluid. The intestines were then removed, and the cavity cleared of the fluid. It was then discovered that a pseudo-membrane of greater thickness than the upper stratum covered over the posterior surface of the pubic arch, the upper portion of the bladder, and then passing over the uterus, completely lined Douglas's pouch, corering the surface of the ovaries with their liga. ments. This membrane was adherent to the subjacent organs, but was easily stripped off, until the left ovary was reached, and to the upper part of this organ the membrane 